\title{
JURISPRUDENCIA AMBIENTAL EN ASTURIAS (SEGUNDO SEMESTRE 2019)
}

\author{
Alejandra Boto Álvarez \\ Profesora Titular de Derecho Administrativo \\ Universidad de Oviedo
}


Sumario: 1. Indefensión, culpabilidad y proporcionalidad en el derecho sancionador ambiental.- 2. El carácter condicional de las subvenciones: ayudas al pastoreo.- 3. Telecomunicaciones: ¿ordenación general o especial?

Para esta crónica se han elegido tres sentencias emanadas en los últimos meses de la sala de lo contencioso-administrativo del Tribunal Superior de Justicia de Asturias (TSJA) con relevancia ambiental y que de alguna manera conectan con las Ilamadas actividades clásicas de la Administración: policía, fomento y servicio público.

\section{INDEFENSIÓN, CULPABILIDAD Y PROPORCIONALIDAD EN EL DERECHO SANCIONADOR AMBIENTAL}

A última hora de la tarde del 24 de abril de 2017, un escape de gases de combustión procedente de unas baterías de coque en instalaciones industriales de Avilés provocaba una considerable alerta en el centro de la ciudad 2 . Tras visita de la Guardería de Calidad Ambiental a la zona, la empresa titular atribuyó la fuga a un fallo durante diez minutos en un sensor y paró completamente la planta, iniciándose inmediatamente las reparaciones. Después del levantamiento del acta de inspección ambiental, la empresa y el Servicio de Control Ambiental intercambiaron distintos escritos relativos a comunicaciones en caso de incidente previstas en la Autorización Ambiental Integrada. En días posteriores al escape, la Consejería de Infraestructuras, Ordenación del Territorio y Medio Ambiente, admitió que el escape había producido "afecciones a la población", e inició una investigación para aclarar la procedencia de la nube contaminante. No es la primera vez que este tipo de incidentes se producen en la zona, pero en esta ocasión los ecos llegaron hasta el Parlamento Europeo y

El trabajo ha sido elaborado en el marco del proyecto de investigación de referencia IDI/2018/000219 correspondiente a una ayuda a organismos públicos de investigación para apoyar las actividades de grupos de investigación en el Principado de Asturias concedida por el Gobierno de este al grupo SPAG (Servicios Públicos, Administraciones y Garantías) que coordina el profesor Tolivar Alas en la Universidad de Oviedo.

2 Puede verse el eco que del incidente se hizo la prensa, por ejemplo, en https://www.efe.com/efe/espana/sociedad/un-escape-de-gas-procedente-arcelormittal-provocala-alarma-en-aviles/10004-3247082. El Servicio de Control Ambiental emitió en su momento un informe dando cuenta de más de veinte llamadas recibidas en su centro de coordinación de emergencias en algo menos de veinte minutos, y de la movilización subsiguiente de SAMU, Policía Local, Bomberos, Protección Civil, helicóptero medicalizado, Cuerpo Nacional de Policía, Guardia Civil, etc. También existe un informe de la Gerencia del Área Sanitaria afectada, sobre las atenciones en los servicios de urgencias, habiendo atendido a cinco personas con síntomas relacionados con el escape y facilitado mascarillas a los usuarios del centro de salud. 
la Comisión, siendo objeto de la pregunta escrita P-003066-17, en mayo de 2017.

Los hechos dieron lugar a un procedimiento administrativo que culminó considerando que los hechos eran constitutivos de la infracción contenida en el artículo 31.2.b) del Real Decreto Legislativo 1/2016, de 16 de diciembre, por el que se aprueba el texto refundido de la Ley de prevención y control integrados de la contaminación, calificada como muy grave, toda vez que se considera constatada la existencia de una afección a la salud de las personas. La Propuesta de Resolución contemplaba una sanción consistente en multa de 400.000 euros.

Frente a la Propuesta de Resolución la empresa presentó alegaciones, que no fueron atendidas y por Resolución de 9 de mayo de 2018 del Consejero de Infraestructuras, Ordenación del Territorio y Medio ambiente se le impuso la sanción referida. Contra dicha Resolución la empresa interpuso recurso de reposición, que fue desestimado por Resolución de 9 de agosto de 2018.

Esa desestimación constituye el objeto del recurso contencioso-administrativo número 633/2018, resuelto por la Sentencia del TSJA número 282/2019, de 8 de abril. La pretensión de la empresa recurrente es que se deje sin efecto la Resolución recurrida o, subsidiariamente, se califique la sanción de grave con una condena en su grado mínimo, pretensiones estas a las que se opone la Administración demandada, Principado de Asturias, representada por el Letrado de sus Servicios Jurídicos.

Para ello se invoca en primer término la nulidad de la Resolución por haberse producido indefensión. El argumento de la recurrente se basa en que la Resolución impugnada en su "Resuelvo" no hace referencia al número del artículo infringido, sino a la norma en sentido genérico (el Real Decreto Legislativo 1/2016). EI TSJA, en atención a que la Resolución sí citaba el artículo vulnerado en concreto (el 31.2.b) tanto en los hechos como en los fundamentos de derecho, considera que se trata de una mera irregularidad procedimental y 
formal que no ha dado lugar a una indefensión real y efectiva (Fundamento de Derecho tercero).

Invoca la actora a continuación la vulneración de lo dispuesto en el artículo 28.1 de la Ley 40/2015, de 1 de octubre, de Régimen Jurídico del Sector Público en relación con el artículo 25.1 de la Constitución Española y, sosteniendo que el escape se había debido a un caso fortuito, entiende que no puede ser sancionada porque no ha concurrido ni dolo ni culpa. El argumento no es acogido por el Tribunal, que hace suyo el razonamiento de la Resolución impugnada ante alegaciones idénticas en vía administrativa. $Y$ así se señala, en el Fundamento cuarto, que

la liberación a la atmósfera se debió a un fallo en una sonda que mide el nivel del agente de lavado. Como consecuencia del fallo de la sonda se interrumpió el aporte de agente de lavado produciéndose emisiones de SO3 a la atmósfera durante unos 15 minutos. Del examen de los datos obrantes en el expediente se concluye que en la instalación no se disponía de un sistema de control del funcionamiento correcto de la sonda, o que advirtiera de su mal funcionamiento [...] Considerando las consecuencias que el deficiente funcionamiento de la sonda puede provocar y de hecho ha provocado [...] la empresa no ha actuado con la diligencia que le es exigible en cuanto al control del correcto funcionamiento de la sonda, estableciendo un sistema que permita detectar un fallo de funcionamiento. Por tanto, debe descartarse el caso fortuito alegado por la empresa como forma de eximirse de responsabilidad en la causación del escape de SO3. Este sistema es el que se ha implementado tras producirse la avería mediante la instalación de niveles visuales, y niveles de alarma sonoros, etc., que sí permiten una verificación del funcionamiento correcto y garantiza al máximo la entrada óptima de ácido sulfúrico a la torre de absorción.

Por último, se alega falta de proporcionalidad en la sanción. La empresa invocaba en respaldo de su tesis el hecho de que el Ministerio Fiscal hubiera acabado archivando diligencias por los hechos. Discutía que existiera por su parte reincidencia, porque "tan solo uno de los diversos expedientes sancionadores previos frente a ella se refiere a emisiones a la atmósfera, sino 
que traen causa de otro tipo de conducta, como son los vertidos al medio fluvial, debiendo valorarse una eventual reiteración infractora -en aras de la proporcionalidad- en relación con las diversas instalaciones y no respecto de la persona jurídica en su conjunto". Frente a ello, el TSJA recuerda que el reproche penal y el administrativo son aspectos distintos de la conducta, e insiste en la reincidencia porque el mismo sujeto había sido sancionado en el plazo de un año por infracciones administrativas en el marco de la Ley 16/2012, de 1 de julio, de prevención y control integrado de la contaminación y por considerar que en efecto se había producido una infracción tipificada como grave por incumplir términos de la autorización ambiental integrada, al no disponer de un plan específico adecuado respecto a la actuaciones y medidas para dar respuesta a las condiciones de explotación en situaciones distintas a las normales que pudieran afectar al medio ambiente, y con el resultado de poner en peligro grave la seguridad o la salud de las personas (Fundamento de Derecho quinto).

\section{EL CARÁCTER CONDICIONAL DE LAS SUBVENCIONES: AYUDAS AL PASTOREO}

En Sentencia de 27 de mayo de 2019, el TSJA resuelve el recurso número 815/2018, presentado contra una Resolución de 9 de diciembre de 2018 de la Consejería de Desarrollo Rural y Recursos Naturales del Principado de Asturias que canceló el compromiso plurianual 2015-2019 adquirido en el marco de una ayuda agroambiental de sistemas de pastoreo racional en superficies de uso común.

La Administración autonómica reaccionó así tras constatar, en una inspección sobre el terreno en 2017, que los animales que el recurrente había identificado uno a uno con su crotal no estaban en el monte. En el acta de control, el recurrente explicó que los animales estaban retenidos en Extremadura por razones de sanidad animal. Se comprobó que en 2016 ya había presentado escritos alegando "retraso" en la llegada de los animales al pasto. En 2018 vuelve a declarar animales identificados individualmente para comunicar que van a acceder a los pastos comunales para percibir la ayuda y en mayo de 2018 , reitera que van a "sufrir retraso" en el acceso a los pastos por estar pendiente del saneamiento y que "comunicará" la fecha en que acceden. Al realizarse los 
controles administrativos, a 31 de agosto los animales no habían entrado en Asturias y no hubo ninguna otra comunicación del interesado.

El demandante sostiene que su comportamiento estaba justificado por motivos sanitarios de inmovilización de la cabaña ganadera, que había comunicado fehacientemente a la Administración. Sin embargo, el TSJA considera que no basta con la comunicación del problema de saneamiento y el retraso de la incorporación del ganado a los pastos estivales hasta su solución por la autoridad competente, cuando esta situación se ha mantenido en el tiempo sin que la parte demandante haya aportado pruebas para atribuirla a la conducta de un tercero o de fuerza mayor durante cada uno de los períodos inspeccionados (Fundamento de Derecho tercero).

Y así, recordando que la subvención no responde a una causa donandi, sino a la finalidad de intervenir en la actuación del beneficiario a través de unos condicionamientos o de un modus, libremente aceptado por aquél, desestima el recurso y condena en costas a la parte demandante con un límite de 300 euros (Fundamento de Derecho cuarto).

\section{TELECOMUNICACIONES: ¿ORDENACIÓN GENERAL O ESPECIAL?}

El último de los fallos a analizar en estas páginas, de 20 de mayo de 2019, resuelve el recurso de apelación 91/2019, presentado contra Sentencia de 25 de enero del mismo año del Juzgado contencioso-administrativo número 6 de Oviedo. La sentencia de instancia había desestimado recurso en procedimiento ordinario número 76/18 contra una resolución municipal de legalización de licencia para estación base de telefonía móvil, adoptada esta legalización a su vez en ejecución de la Sentencia de 15 de julio de 2015 (procedimiento ordinario número 112/2014) del mismo Juzgado.

Las alegaciones del recurrente tratan de someter a revisión la licencia originaria de la estación y de confrontar su instalación con las prescripciones del PGOU en cuanto a alturas, pero sobre todo a condiciones de uso. La revisión no puede proceder por haberse ordenado la legalización en una sentencia firme (la de 2015), y respecto al marco jurídico-urbanístico al que debe contraerse ese procedimiento de legalización, el TSJA entiende que no puede ser el Plan General, que no estaba en vigor cuando se concedió la licencia y además se 
refiere a las propias edificaciones y no tanto a las instalaciones situadas por encima de su altura máxima (Fundamento de Derecho tercero), sino al Plan Especial de Ordenación de Instalaciones de Telecomunicaciones.

Y el razonamiento lleva a desestimar el recurso, con condena de las costas devengadas en la alzada a la parte apelante, con un límite común para cada una de las partes comparecidas como apelada y coapeladas de 1.000 euros. 